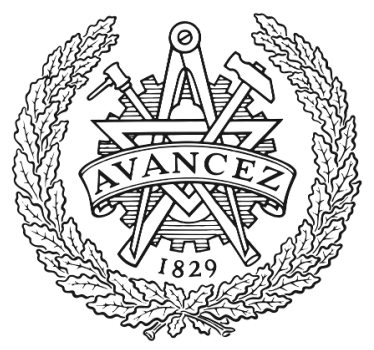

CHALMERS

UNIVERSITY OF TECHNOLOGY

\title{
Conceptualizing Embodied Automation to Increase Transfer of Tacit knowledge in the Learning Factory
}

Downloaded from: https://research.chalmers.se, 2023-04-26 15:10 UTC

Citation for the original published paper (version of record):

Fasth Berglund, Å., Thorvald, P., Billing, E. et al (2018). Conceptualizing Embodied Automation to Increase Transfer of Tacit knowledge in the Learning Factory. IEEE Conference on Intelligent Transportation Systems, Proceedings, ITSC: 358-364. http://dx.doi.org/10.1109/IS.2018.8710482

N.B. When citing this work, cite the original published paper. 
See discussions, stats, and author profiles for this publication at: https://www.researchgate.net/publication/327844155

\section{Conceptualizing Embodied Automation to Increase Transfer of Tacit knowledge in the Learning Factory}

Conference Paper $\cdot$ September 2018

CITATIONS

6 authors, including:

Åsa AB Fasth, Fast-Berglund

Chalmers University of Technology

110 PUBLICATIONS 594 CITATIONS

SEE PROFILE

Georg Weichhart

Profactor $\mathrm{GmbH}$

76 PUBLICATIONS 513 CITATIONS

SEE PROFILE

Some of the authors of this publication are also working on these related projects:

Project Sensing Enterprise View project

Project Enterprise Modelling View project

David Romero

Tecnológico de Monterrey

102 PUBLICATIONS 972 CITATIONS

SEE PROFILE 


\section{Conceptualizing Embodied Automation to Increase Transfer of Tacit knowledge in the Learning Factory}

\author{
Åsa Fast-Berglund \\ Production Systems, \\ Chalmers University of Technology, \\ Gothenburg, Sweden \\ asa.fasth@chalmers.se \\ Adam Palmquist
Insert Coin,
Gothenburg, Sweden
adam@insertcoin.se
}

\author{
Peter Thorvald \\ Production Development, \\ University of Skövde, \\ Skövde, Sweden \\ peter.thorvald@his.se \\ David Romero \\ Center for Innovation in \\ Design and Technology, \\ Tecnológico de Monterrey, Mexico \\ david.romero.diaz@gmail.com
}

\author{
Erik Billing \\ Information Technology, \\ University of Skövde, \\ Skövde, Sweden \\ erik.billing@his.se \\ Georg Weichhart \\ Flexible Production Systems, \\ Profactor \\ Studgart, Austria \\ Georg.Weichhart@profactor.at
}

\begin{abstract}
This paper will discuss how cooperative agent-based systems, deployed with social skills and embodied automation features, can be used to interact with the operators in order to facilitate sharing of tacit knowledge and its later conversion into explicit knowledge. The proposal is to combine social software robots (softbots) with industrial collaborative robots (co-bots) to create a digital apprentice for experienced operators in humanrobot collaboration workstations. This is to address the problem within industry that experienced operators have difficulties in explaining how they perform their tasks and later, how to turn this procedural knowledge (knowhow) into instructions to be shared among other operators. By using social softbots and co-bots, as cooperative agents with embodied automation features, we think we can facilitate the 'externalization' of procedural knowledge in human-robot interaction(s). This enabled by the capabilities of social cooperative agents with embodied automation features of continuously learning by looking over the shoulder of the operators, and documenting and collaborating with them in a non-intrusive way as they perform their daily tasks.
\end{abstract}

Keywords-Embodied Automation, Agent-based Systems, Robot Systems, Collaborative Robots, Co-Bots, Software Robots, Softbots, Social Robots, Knowledge Transfer, Tacit Knowledge, Game-based Activities, Motivation.

\section{INTRODUCTION}

Sharing information and knowledge within an organization can be challenging [1]. Knowledge is different from information, and sharing it requires different sets of methods and tools that are not always supported by the features of (computer) information systems [1]. Hence, there are several approaches and strategies to share knowledge according to different academic disciplines or fields of study like Knowledge Management (KM), Knowledgebased Engineering (KBE), and Human Resources Information Systems (HRIS)

From a KM perspective, information is only gathered because someone in the organization looks at it and makes use of it (e.g. for decision-making, for learning, for quality assurance). So the value of information is weighed against the cost of managing and using it. Therefore, systems that enhance the effectiveness of decision-making and learning, and increase productivity of knowledge, are considered more valuable [2].
From a KBE perspective, "sharing knowledge" can create a better way to work (i.e. procedures $\&$ best practices), continuous improvements (i.e. learnings), and a feeling of empowerment among the operators (i.e. motivation for learning and sharing knowledge) [3].

From a HRIS perspective, "sharing knowledge" can create a better workplace by collecting, storing, maintaining, retrieving, and validating the data needed by a (learning) organization about its human resources, personnel activities, and organizational units' characteristics for better managing its human capital [4].

While direct instruction between operators certainly remains as an important way of knowledge transfer (i.e. through the mentorapprentice training model); we see large opportunities in using digitalization and collaborative ICT technologies to increase knowledge transfer and documentation in the learning (smart) factory / organization of the $21^{\text {st }}$ Century.

For this, Information Support Systems (ISS) and collaborative ICT-tools are vital. To adopt such ISSs, shared knowledge needs to be externalized and combined into the system continuously [5] [6]. A big problem in industry today is how and when to collect and transform this knowledge into the ISS [6]. Studies show that the operators, and middle management, have a hard time to summarize their experiences and insights with help of text and pictures [7].

Some additional factors "limiting" knowledge sharing and knowledge transfer are that the operators find it hard to put their knowledge into words (text) with limited space in a computer information system (textbox); the lack of standardization when collecting and documenting knowledge; that the operators think it takes a lot of time from their "real" working tasks to document their knowledge; that the operators use their knowledge as an assurance to stay relevant, indispensable, within a company to mention a few [8] [9]. 
If the collection of information could be done autonomously and automatically with the help of social softbots ${ }^{I}$ [10] [11] and co-bots ${ }^{2}$ [12], this could facilitate knowledge externalization (i.e. from tacit to explicit knowledge) by means of knowledge socialization (i.e. from tacit to tacit knowledge) [5] in a natural "human-robot - conversation - interaction". In this scenario, industry would be able to standardize work tasks according to best practices of the operators, and this would increase quality and productivity for industry.

The main aim of this paper is to present a "concept design" of a knowledge sharing strategy, illustrated in Fig. 1, of a cooperative agent-based system with social skills and embodied automation ${ }^{3}$ features [13] that motivates and it is trusted by the operators in order to share their tacit knowledge to an ISS and enable knowledge externalization.

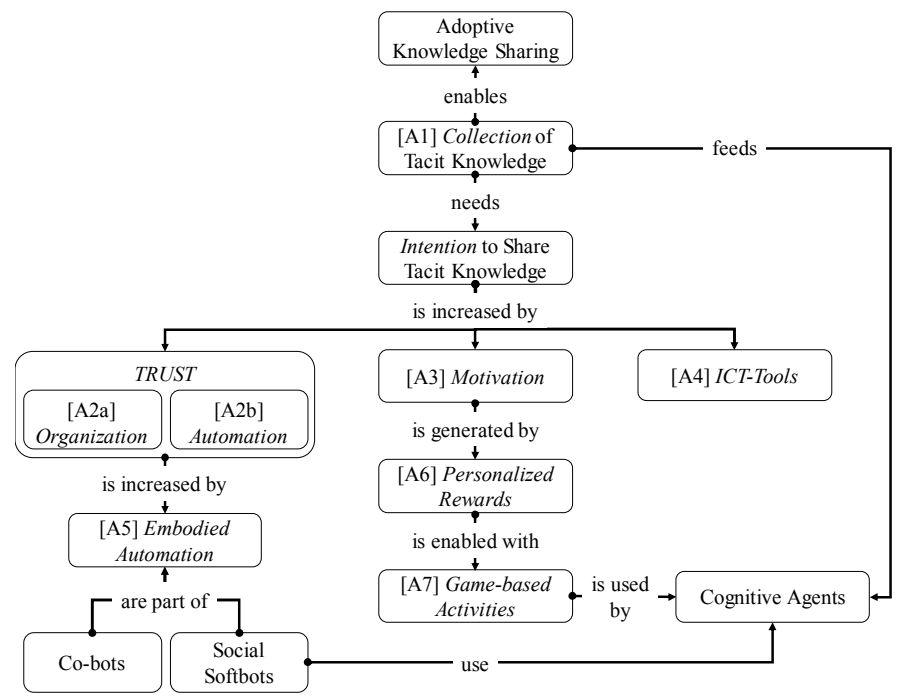

Fig. 1. Conceptual Overview of the Proposed Knowledge Sharing Strategy to Enable Adaptive Tacit Knowledge Transfer

\section{BASE CONCEPTS:}

\section{COOPERATIVE AGENT-BASED SYSTEMS AND EMBODIED AUTOMATION}

Humans and their interactions with other human and artificial agents, such as softbots [10] [11] and co-bots [12], represent in many cases complex cooperative agent-based systems [e.g. 14]. Sharing tacit knowledge and transforming it into an effective and efficient ISS, within such agent-based systems, is a challenging endeavor according to the KM literature. Therefore, in this paper, we propose a knowledge sharing strategy, which codifies skill-, rule-, and knowledge- based behaviors and experiences from the operators in order to enable the collection and transfer of tacit knowledge into other cognitive agents (i.e. other humans and/or artificial intelligences (e.g. social softbots)). Then, these cognitive agents codify and personalize the knowledge and transfer it into an ISS. Does it sound easy? - Well, it is important to have a $K M$ strategy when implementing these kind of ISSs, since knowledge barriers [8] exists in every organization, from technological to organizational ones. For these reasons, we use seven assumptions and their interrelations (see Fig. 1 - (A1) to (A7) boxes) in order to determine the important areas and relations to consider when designing an adaptive ISS ${ }^{4}$ [15] for operators. The first step is to be able to collect tacit knowledge from the operators. This can be done by using different ICT-tools that are autonomous, easyto-use and use different multimedia principles when collecting information. In cognitive multi-agent systems [16] [17], softbots and co-bots can be used to embody the automation [13], and we believe that "trust" to share tacit knowledge to an ISS increases if the information is feed through "smart cognitive agents" [14] that are adaptable to the operators. Such (agent) intelligence allows the cognitive multi-agent system to know what question to ask and what comments to say in order to trigger the motivation of the operator. This is done based on game-based activities and personal rewards such as empowerment, usefulness, recognition and sense of competence. These assumptions have been tested one by one, but not all together. This is part of the future research within this area.

\section{ASSUMPTIONS FOR DESIGNING}

ADAPTIVE INFORMATION SUPPORT SYSTEMS

\section{Assumption 1 (A1): \\ "Tacit knowledge can be shared and collected"}

Two terms commonly wrongly used interchangeably in KM literature are "knowledge sharing" and "knowledge transfer". In this paper, and according to Paulin and Sunneson [9]'s definitions, we define knowledge sharing - as "an exchange of knowledge between two individuals, one who communicates knowledge and other one who assimilates it", and knowledge transfer - as "the focused, unidirectional communication of knowledge between individuals, groups, or organizations such that the recipient of knowledge has a cognitive understanding, has the ability to apply the knowledge, or applies the knowledge".

In order to create a successful knowledge transfer strategy, tacit knowledge needs to be collected and transformed into information that can be stored in an ISS. The term knowledge is heavily debated and there are a lot of different meanings and definitions.

In this paper, knowledge - is defined as "the understanding of situations and their context framed by experience, values, contextual information and insights to evaluate and incorporate new experiences and information" [18-20]. Knowledge can be further divided into two main types [21]: (a) tacit knowledge, and (b) explicit knowledge. Polanyi [21] argues that knowledge contains an explicit and tacit dimension. Explicit knowledge can be explained as the externalization of knowledge to be shared since it can be codified in - words, numbers, etc. [22]. Tacit knowledge is often defined as uncodeable, intuitive and nonverbalized, e.g. rules-of-thumb, gut-feelings, personal skills [23].

\footnotetext{
${ }^{1}$ Social Soft-bots are software robots able to collect, analyze, and transform knowledge into information, which can be managed by an information support system [10] [11].

${ }^{2}$ Co-bots are industrial collaborative robots able to share the same workspace, workstation and workpiece as the operator [12].
}

\footnotetext{
${ }^{3}$ Embodied Automation is a type of (smart) automation that aims to think and behave in a human-life form (anthropomorphism) autonomously (e.g. AI) [13]. ${ }^{4}$ An Adaptive Information Support System is an information system capable of providing background information and decision support appropriate to the user needs based on processes that adapt to the individual preferences of users rather than to some general rules for all users or user groups [15].
} 
Tacit knowledge is hard to share since it is connected to skills and experiences. Rasmussen [24] also talks about dividing the operator's tasks into skill-, role-, and knowledge-based performances where skill and knowledge can be seen as tacit knowledge and rule-based tasks can be seen as instructions or explicit knowledge.

Skill-based behavior is often connected to senses, e.g. it feels right when I mount the screws; I hear that something is wrong with the machine; it smells wrong. The skill-based tasks are also connected to "intuitive cognitive behavior".

Knowledge-based behavior can be connected to both explicit and tacit knowledge. An example of tacit-tacit knowledge is "we have always done it this way, not as the written instructions".

Two main KBE strategies, or general knowledge extraction approaches, are "codification" and "personalization" [25]. These strategies can be combined in order to create a good knowledge transfer to an ISS [26].

Our assumption is that it is possible to collect tacit knowledge and thereby transform and transfer it into an ISS for its later share across the organization. This can be done by using non-invasive and interactive ICT-solutions if the knowledge barriers are low; this is connected to assumption A2b in terms of "social softbots" following e.g. an "apprenticeship learning" style approach.

\section{Intention to Share Tacit Knowledge $(A 2 a, A 3 \& A 4)$}

The intention to share tacit knowledge can depend on many factors; it can for example be divided into personal intentions, organisational intentions, and intra-organisational intentions [27]. Other factors influencing the intention to share knowledge are education, experience, training, autonomous motivation, shortterm goals, trust of co-workers, and rewards [28-29]. In this paper, the intention to "share knowledge" is divided into to three different assumptions: Trust (A2a), Motivation (A3), and ICTtools (A4) - as illustrated in Fig. 2.

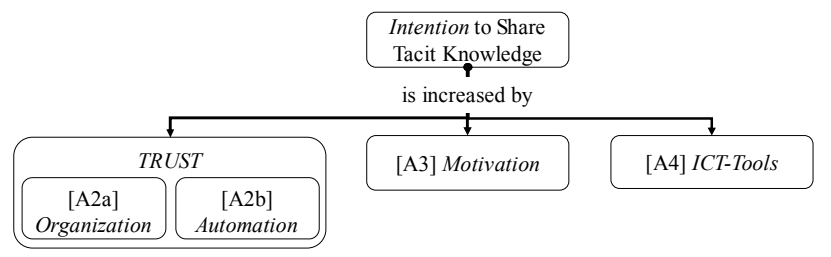

Fig. 2. The Three Areas that Increase Tacit Knowledge Transfer

\section{"Knowledge transfer increases with trust in organization"}

Trust exists when individuals perceive that their co-workers possess such qualities of "trustworthiness", and believe that the co-workers would repay them by doing the same thing when they share knowledge with others [27]. Given that sharing tacit knowledge is a form of sharing power with others, it takes trust for individuals to share tacit knowledge with their co-workers, because trust may reduce perceived uncertainty, facilitate risktaking behaviors, and foster a constructive orientation [30]. In addition, the management in organization is important in order to feel trust for sharing tacit knowledge [28].
Assumption 3 (A3):

"Knowledge transfer increases if the operators are motivated"

In order to increase knowledge transfer in an organization, it is important to take into account employees' motivation for knowledge transfer [18]. Results from a study [31] show that "motivation" differs depending on if the operator is sharing tacit or explicit knowledge. Moreover, the sense of achievements and challenges of work trigger people to share knowledge in parallel groups.

The concept of motivation is determined by an individual's choice to "engage" in an activity, and the intensity of effort or persistence in that activity. Motivation can be divided into three major categories: (i) intrinsic, (ii) extrinsic, and (iii) social [32]. Within these categories, different theories of motivation can be found [33] [34].

Intrinsic motivation refers to motivation that is engaging because it is personally rewarding; essentially, performing an activity for its own sake rather than the desire for some external reward - like money. Intrinsic motivation is crucial when tacit knowledge is transferred in and between teams [35].

Extrinsic motivation occurs when an individual is motivated to perform a behavior or engage in an activity to either receive a reward or evade a punishment. Social motivation applies to the human need to socialize with other individuals and to feel accepted by them. These interactions are regarded as "social behaviors", which address other people with the purpose of getting a response [35].

Assumption 4 (A4):
"The ICT-tools used for knowledge transfer
must be as easy as sharing it with a co-worker"

Nonaka and Takeuchi [5] have provided a framework for describing a KM model that allows explaining the process of transferring knowledge from "implicit" to "explicit", and incorporating knowledge again. From an organisational point of view - and taking 'information systems' theory into account the learning organization approach [36] considers two levels. In the Level 1, workers working in the business environment will use their available tacit and explicit knowledge (available in the organization) to fulfil their work. In case of facing a situation that cannot be handled, information describing the situation has to be made explicit and needs to be transferred (communicated) to the Level 2, the management level. Here, new knowledge is created by communicating elements, which hamper further work in the business environment, explicitly to others. This approach takes also a distributed organisational knowledge base into account, which is comprised of all information systems installed in the organization and that contain the explicit knowledge of the organizational memory [36].

While there has been a widespread argument that ICTs are "limited" when it comes to sharing tacit knowledge, Hildrum [37] questions this view and demonstrates that ICTs can constitute effective mediators for tacit knowledge. Hence, well-integrated information management and communication techniques can significantly contribute to support an overall KM program [38], and create a positive cost-benefit business case for information gathering for its later transformation into knowledge. 
For example, results from earlier studies within ten industrial cases show that over $80 \%$ of all tasks that are performed with the operators own experience (own information) [39]. This is in line with other studies [40], which indicate that the personnel do not always use information systems in an appropriate way.

Moreover, according to Thorvald et al. [41], it is believed that the usage of information systems increases if the ICT is mobile and close to the operator. ICT tools hold the possibility to save time through quick and effective information flows that synchronize the work and enable a proactive work setting [42].

Presentation of information can be broken-down into two parts: (i) carrier, and (ii) content - of information [43]. Carrier concerns to the medium of information (e.g. paper, screens, and PDAs), while the content concerns the mode of information (e.g. text, pictures, sound, or movies).

Furthermore, a matrix developed by Paul [31] describes two modes of sharing knowledge: (i) knowledge application, and (ii) knowledge development. In both modes, the matrix provides examples of ICT-tools for supporting knowledge transfer. For the particular mode of knowledge development, and sequential settings, Paul [31] has proposed "intelligent agents". In addition, Romero et al. have presented in [44] eight different types of interactions between operators and automation, two of them are the social operator (operator + social networks) and the smarter operator (operator + intelligent personal assistant), which can be used in this scenario in order to increase the knowledge transfer.

We propose cognitive agents as "social soft-bots", which can be defined as more embodied then other intelligent agent-based systems in order to get a more personal assistant-like automation solution.

Increase trust through embodied automation $(A 2 b \& A 5)$

In order for the operator to trust automation, our assumption and bet is to create an embodied automation solution containing both social softbots and co-bots following a human-centered automation approach [45-48]. This to be able to collect different kinds of data as a learning organization, and for the operator to get help, both physical and cognitive if needed. The concept of the embodied automation is illustrated in Fig. 3.

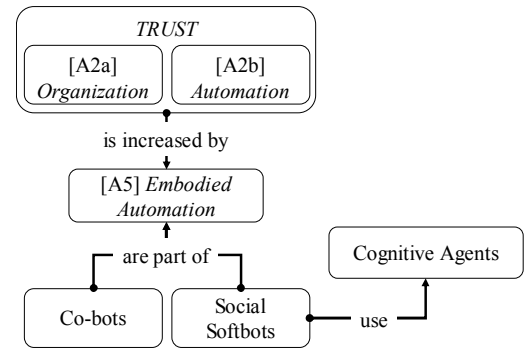

Fig. 3. Trust in Automation

Assumption 2b (A2b):
"Knowledge transfer increases with trust in automation"

By receiving "positive feedback" (e.g. encouragement) from colleagues, the individuals build self-confidence and confidence in their peers. This increases a sense of trust in others and the belief that colleagues are ready to help them [29]. If the human should trust the automation and share knowledge, it is vital that a social softbot in combination with a cognitive agent can give the same kind of positive feedback as the colleagues. This requires a smart AI system that collects and expresses positive feedback in the same way as a human colleague. This puts requirements on the technology to be trustworthy. "Trust" in automation involves other factors that relate specifically to technologies and information quality, e.g. reliability, validity, utility, robustness, and false-alarm rate [49]. There is a high risk when a company acquires new technologies without having a clear strategy on how to implement these technologies into the working environment due to its lack of experience in standardized work [50] [51]. This could turn into irritation among operators and decreased trust in automation [49].

\section{Assumption 5 (A5):}

"Trust in automation is increased if the automation is embodied"

Advances in cognitive science, social robotics, cognitive modelling and AI during the last 30 years have indicated the importance of embodiment, suggesting that the embodiment of ICT, e.g. in the form of social robots, can have drastic effects on communication and knowledge transfer, and as such, has focused on this fact when proposing AI systems rather than the traditional software view on human intelligence.

In a review by $\mathrm{Li}$ [52], the effects of physical embodiment were analyzed, comprising results from 33 experimental studies with physical and virtual agents. A majority of the studies (73\%) showed a preference for the physical embodiment, compared to virtual or disembodied agents. It is argued that intelligence and consciousness is dependent on a physical body, which can interact with the world. Arguably, this might also have an impact on human interaction with a system. The presence of a physical body effects the behavior of the human interacting with the system, and the physical embodiment of the system may be especially important when it comes to communication of tacit knowledge.

Ultimately, we propose that the interaction with an embodied agent is easier / more effective than the interaction with a nonembodied agent for "sharing knowledge" between operators working in industrial settings. Furthermore, as a physical help for the operator, we propose co-bots that can be used in near collaboration with the operator. In order to make the co-bot flexible, we also propose a "moving co-bot" as well. Fig. 4 shows some concepts that can be put together. The length of the co-bot is also essential. The most famous humanoid robot today might be "Pepper". This robot mostly attracts younger children [53] that can depend on the length of the robot; therefore, we propose a 'co-bot' that is at least 160 centimeter in order to attract older people and to be seen as an equal rather than an entertainment robot.

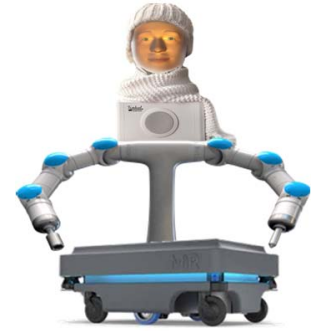

Fig. 4. Hybrid Concept of Embodied Automation combining (top-down) Furhat Robotics, SciMotion Robotics and MiR Robotics 
Increase intention to share tacit knowledge through motivation and game-based activities (A6 \& A7)

Motivation is an important factor to increase the intention to share knowledge. There are personalized and organisational motivation factors. In this paper, we discuss the motivation from a "personal perspective" with game-based activities as a trigger for that motivation as illustrated in Fig. 5.

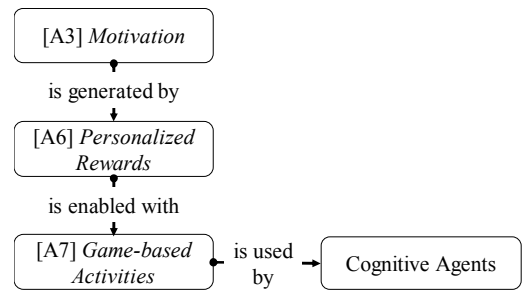

Fig. 5. Motivation as an Enabler for Knowledge Transfer

\begin{tabular}{c} 
Assumption 6 (A6): \\
"Motivation can be increased by using personal rewards" \\
\hline
\end{tabular}

Social activities like competition, social interaction, and collaboration are ordinary and essential in game-design and may influence human behavior and motivation [54-56].

Knowledge transfer could be hampered by individuals who wants to sustain competitive advantages, which they possess through their tacit knowledge base [57]. In order to share their knowledge, some kind of personal reward is needed. Šajeva [29] shows that intrinsic rewards have significant positive effect on knowledge transfer among employees and can help to construct a reward system with following characteristics: A sense of (i) belonging and sharing common values, (ii) achievement and success, (iii) competence, (iv) usefulness, and (v) respect and recognition.

Assumption 7 (A7):
"Motivation and personal rewards can be enabled
by using game-based activities"

In gaming, motivation has been from the start a central part of the experience, and there is much exploration done in order to get the players more motivated for a product [54-56]. Games are an interactive system that responds fast to the user's action to get them motivated and engaged. In a short brief, the digitalization of games did put the medium under economic pressure. If the player did not feel engaged enough with the digital games, they merely could choose a different one in a matter of minutes. That competition within the medium forced the game developers to look into different "design principles" born out of psychology and behavioral science. This brief segment of game history made core game design, within a couple of decades, sophisticated design for "human motivation."

Today, games are common in various forms of training and higher education in different sectors. Game-based thinking has even become commonly used to support young persons who are Not in Education, Employment, or Training (NEETS) to help them to re-adjust to society as well for pupils with neurodevelopmental disorders [58] [59].
In particular, digital games combine and trigger three types of motivations simultaneously to get the player more engaged to interact with a product: (i) extrinsic rewards such as badges, levels, and points to enhance the player engagement, (ii) intrinsic rewards, including giving players autonomy, to allow the feeling of competence and sense of control to increase the player's impressions of achieving mastery, and (iii) social motivation using collaboration and competition (i.e. coopetition), as well as other forms of interactions between players to raise social interactions [56].

Game-based learning, such as serious games / gamification, are applying the design concepts of digital games to increase individual's motivation for different, sometimes mundane, tasks or as a nudge for human behavior change [56].

\section{CONCLUSIONS \& FURTHER RESEARCH}

This paper proposed a "concept" and a "strategy" in order to increase the autonomous transfer of tacit knowledge within (learning) organizations. Moreover, it discussed the importance of embodiment and anthropomorphism [60] when evaluating the operators' tendencies towards sharing - tacit knowledge. Ultimately, the paper aims to contribute to find an effective and efficient channel for sharing and documenting tacit knowledge that workers feel comfortable with and where knowledge transfer is effective. In line with that aim, we suggest a concept where the investigation is done in two steps:

- Explore the effects on social interaction between human and agent where the latter is either non-embodied or embodied.

- Explore the effects that different types of embodiment, such as different levels of anthropomorphism, have on social interaction(s) between human and agent.

While we do expect to find in further research primarily qualitative differences in the social interaction between a human and an agent (e.g. a social softbot), we do not expect that the interactions with a non-embodied agent to be unsuccessful, but rather to find that the interaction with embodied agents will have higher likeness to humans (cf. anthropomorphism), and therefore, to be more effective. Furthermore, in order to create motivation to share tacit knowledge, game-based activities are vital. These aforementioned motivational triggers can be personalized if the personal agent updates what triggers and motivates the worker to share his/her tacit knowledge.

However, we are well aware that in order to reach this $K M$ vision, several technical and organizational challenges need to be overcome first. The collection of "tacit knowledge" from workers through "deep learning" capable agents is not available now and it requires "big data" in order for the agents to become "self-learning". Moreover, some systems exist that are capable of classifying workers' activities from a closed set of possible activities. Yet, it is not possible to understand the intentions behind these activities. 
On more organizational issues, the inclusion of game-based activities needs to be implemented in (computer) information systems. This includes interfaces for workers that show a gameoriented interface, instead of widgets. Another creative task to be accomplished, among many others, is to intertwine the fun activities with strictly work related activities. Furthermore, it still an ethical dilemma about what to do with the data that the agent is collecting, if the agent is becoming more of an employee; sensitive data might be collected so this issue needs to be considered and addressed.

Cognitive agents - that realize the above challenges on a technical level are needed. While some cognitive architectures (e.g. Soar [61]) are available for implementing simple humanlike reasoning processes, the combination of embodiment, with motivation triggers based on game-based interaction approaches, and (cognitive) reasoning has not been implemented yet.

\section{ACKNOWLEDGEMENTS}

This research work is partly funded by the Stena Industry Innovation Lab (SIILab), co-funded within the Production 2030, Vinnova and Stenastiftelsen Swedish research programs, and by the Pro ${ }^{2}$ Future Lab, co-funded within the Austrian COMET program - Competence Centers for Excellent Technologies under the auspices of the Austrian Federal Ministry of Transport, Innovation and Technology, the Austrian Federal Ministry for Digital and Economic Affairs and of the Provinces of Upper Austria and Styria. The COMET program is managed by the Austrian Research Promotion Agency FFG (Contract Nr. 854184).

\section{REFERENCES}

[1] R. McDermott. "Why Information Technology Inspired But Cannot Deliver Knowledge Management". California Management Review, Vol. 41, pp. 103-117, Summer, 1999.

[2] V.Y. Haines, A. Petit. "Conditions for Successful Human Resource Information Systems". Human Resource Management, Vol. 36, pp. 261$275,1997$.

[3] D.J. Leach, T.D. Wall, P.R. Jackson. "The Effect of Empowerment on Job Knowledge: An Empirical Test Involving Operators of Complex Technology". Journal of Occupational and Organizational Psychology, Vol. 76, pp. 27-52, 2003.

[4] K.A. Kovach, C.E. Cathcart. "Human Resource Information Systems (HRIS): Providing Business with Rapid Data Access, Information Exchange and Strategic Advantage". Public Personnel Management, Vol. 28, pp. 275-282, 1999.

[5] I. Nonaka, H. Takeuchi. "The Knowledge Creating Company: How Japanese Companies Create The Dynamics Of Innovation”. 1995.

[6] D. Bowen, E. Lawler. "The Empowerment of Service Workers: What, Why, How, and When". Sloan Management Review, Vol. 33, pp. 31-39, 1992.

[7] Å. Fast-Berglund, U. Harlin, S. Mattsson, C. Groth, M. Åkerman, P. Gullander. "Creating a Structured Meeting Arena for Knowledge Transfer". The Sixth Swedish Production Symposium, 2014.

[8] R. Andreas. "Three Dozen Knowledge Sharing Barriers Managers Must Consider". Journal of Knowledge Management, Vol. 9, pp. 18-35, 2005.

[9] D. Paulin, K. Sunneson."Knowledge Transfer, Knowledge Sharing and Knowledge Barriers - Three Blurry Terms in KM". The Electronic Journal of Knowledge Management, 10(1):81-91, 2012.

[10] J.H. Kim. "Ubiquitous Robot". In: Reusch B. (Eds.) Computational Intelligence, Theory and Applications. Advances in Soft Computing, Vol. 33, Springer, 2005.
[11] R.J. Rabelo, D. Romero, S.P. Zambiasi. "Softbots Supporting the Operator 4.0 at Smart Factory Environments". IFIP, AICT 536, Part II, pp. 456-464, 2018.

[12] ISO/TS 15066:2016 Robots and Robotic Devices - Collaborative Robots https://www.iso.org/standard/62996.html

[13] S.R. Ellis. "Anthropomorphic Robot Design and User Interaction Associated with Motion”. Report: NASA/TM-2016-219426.

[14] D. Romero, T. Wuest, J. Stahre, D. Gorecky. "Social Factory Architecture: Social Networking Services and Production Scenarios through the Social Internet of Things, Services and People for the Social Operator 4.0". IFIP AICT 513, Part I, pp. 265-273, 2017.

[15] I. Šūpulniece, J. Grabis. "Discovery of Personalized Information Systems Usage Patterns". Proceedings of the $16^{\text {th }}$ International Conference on Information and Software Technologies, Lietuva, Kaunas, pp. 25-32, 2010.

[16] E. Hollnagel, D. Woods. "Joint Cognitive System: Foundations of Cognitive Systems Engineering”. London: Taylor and Francis, 2005.

[17] A.T. Jones, D. Romero, T. Wuest. "Modeling Agents as Joint Cognitive Systems in Smart Manufacturing Systems". Manufacturing Letters, Vol. 17, pp. 6-8, 2018.

[18] N.J. Foss, D.B. Minbaeva, T. Pedersen, M. Reinholt. "Encouraging Knowledge transfer among Employees: How Job Design Matters". Human Resource Management, Vol. 48, pp. 871-893, 2009.

[19] T. Davenport, L. Prusak, "Working Knowledge: How Organizations Manage What They Know”. Vol. 1, 1998.

[20] F. Lehner, R.K. Maier. "How Can Organizational Memory Theories Contribute to Organizational Memory Systems?". Information Systems Frontiers, Vol. 2, pp. 277-298, 2000.

[21] M. Polanyi. "The Logic of Tacit Inference". Philosophy, Vol. 41, pp. 1$18,2009$.

[22] G. Hedlund. "A Model of Knowledge Management and the N-Form Corporation”. Strategic Management Journal, Vol. 15, pp. 73-90, 1994.

[23] T. Haldin Herrgard. "Difficulties in Diffusion of Tacit Knowledge in Organizations". Journal of Intellectual Capital, Vol. 1, pp. 357-365, 2000.

[24] J. Rasmussen. "Skills, Rules, and Knowledge; Signals, Signs, and Symbols, and other Distinctions in Human Performance Models". IEEE Transactions on Systems, Man, and Cybernetics, Vol. SMC-13, pp. 257 266, 1983.

[25] G. Jens, R. Thomas. "The Knowledge Retrieval Matrix: Codification and Personification as Separate Strategies". Journal of Knowledge Management, Vol. 9, pp. 133-143, 2005.

[26] M.T. Hansen, N. Nohria, T. Tierney. ""What's Your Strategy for Managing Knowledge?”. Harvard Business Review, Vol. 77, pp. 106-116, 1999.

[27] C.-P. Lin. "To Share or Not to Share: Modeling Tacit Knowledge Transfer, its Mediators and Antecedents". Journal of Business Ethics, Vol. 70, pp. 411-428, 2007.

[28] T. Nesheim, L.J. Gressgård. "Knowledge Transfer in a Complex Organization: Antecedents and Safety Effects". Safety Science, Vol. 62, pp. 28-36, 2014.

[29] S. Šajeva. "Encouraging Knowledge Transfer among Employees: How Reward Matters". Procedia - Social and Behavioral Sciences, Vol. 156, pp. 130-134, 2014.

[30] R.M. Morgan, S.D. Hunt. "The Commitment Trust Theory of Relationship Marketing”. Journal of Marketing, Vol. 58, pp. 20-38, 1994.

[31] H. Paul. "Why Share knowledge? The Influence of ICT on the Motivation for Knowledge Transfer". Knowledge and Process Management, Vol. 6, pp. 91-100, 1999.

[32] R.M. Ryan, E.L. Deci. "Selfdetermination Theory and the Facilitation of Intrinsic Motivation, Social Development, and Well-being". American Psychologist, 55(1):68-78, 2000.

[33] J. Vassileva. "Motivating Participation in Social Computing Applications: A User Modeling Perspective". User Modeling and User-Adapted Interaction, 22(1): 177-201, 2012. 
[34] K. Ling, G. Beenen, P. Ludford, X. Wang, K. Chang, X. Li, et al. "Using Social Psychology to Motivate Contributions to Online Communities". Proceedings of the ACM Conference on Computer Supported Cooperative Work, pp. 212-22, 2004

[35] M. Osterloh, B.S. Frey. "Motivation, Knowledge Transfer, and Organizational Forms". Organization Science, Vol. 11, pp. 538-550, 2000.

[36] J.M. Firestone, M.W. McElroy. "Doing Knowledge Management". The Learning Organization, Vol. 12, pp. 189-212, 2005.

[37] J.M. Hildrum. "Sharing Tacit Knowledge Online: A Case Study of e-Learning in Cisco's Network of System Integrator Partner Firms". Vol. 16, 2009

[38] M. Milton. "Tacit Knowledge transfer: Techniques for Putting a Powerful Tool in Practice". International Journal of Development and Learning in Organizations, Vol. 24, pp. 24-26, 2010.

[39] Å. Fasth-Berglund, J. Stahre. "Cognitive Automation Strategy for Reconfigurable and Sustainable Assembly Systems". Assembly Automation, Vol. 33, pp. 294-303, 2013.

[40] M. Karlsson, S. Mattsson, A. Fast-Berglund, J. Stahre. "Could the Use of ICT Tools be the Way to Increase Competitiveness in Swedish Industry?". IFAC Proceedings Volumes, Vol. 46, pp. 179-186, 2013.

[41] P. Thorvald, A. Brolin, D. Högberg, K. Case. "Using Mobile Information Sources to Increase Productivity and Quality". Proceedings of the $3^{\text {rd }}$ International Conference on Applied Human Factors and Ergonomics, Miami, Florida, USA, 2010.

[42] G. Nordin, T. Fässberg, Å. Fasth, J. Stahre. "IPod Touch-an ICT Tool for Assembly Operators in Factories of the Future-Technical Concepts and Requirements". Proceedings of the $3^{\text {rd }}$. CIRP Conference on Assembly Technologies and Systems, 2010.

[43] A. Fast-Berglund, T. Fässberg, F. Hellman, A. Davidsson, J. Stahre "Relations between Complexity, Quality and Cognitive Automation in Mixed-Model Assembly". Journal of Manufacturing Systems, Vol. 32, pp. 449-455, 2013.

[44] D. Romero, J. Stahre, T. Wuest, O. Noran, P. Bernus, Å. Fast-Berglund D. Gorecky. "Towards an Operator 4.0 Typology: A Human-Centric Perspective on the Fourth Industrial Revolution Technologies". International Conference on Computers \& Industrial Engineering (CIE46) Tianjin, China, pp. 1-11, 2016.

[45] C.E. Billings. "Aviation Automation: The Search for a Human-Centered Approach". 1996.

[46] T.B. Sheridan, R. Parasuraman. "Human-Automation Interaction". Reviews of Human Factors and Ergonomics, 1(89):89-129, 2015.

[47] R. Parasuraman, V. Riley. "Humans and Automation: Use, Misuse Disuse, Abuse". Human Factors: The Journal of the Human Factors and Ergonomics Society, 39(2):230-253, 1997.

[48] D. Romero, P. Bernus, O. Noran, J. Stahre, Å. Fast-Berglund. "The Operator 4.0: Human Cyber-Physical Systems \& Adaptive Automation Towards Human-Automation Symbiosis Work Systems". IFIP AICT 488, pp. 677-686, 2016.

[49] R. Parasuraman, T.B. Sheridan, C.D. Wickens. "Situation Awareness, Mental Workload, and Trust in Automation: Viable, Empirically Supported Cognitive Engineering Constructs". Journal of Cognitive Engineering and Decision Making, Vol. 2, pp. 140-160, 2008.

[50] H.V. Garrido, A. Fasth-Berglund. "ICT-Tools Support Toyota Way Principle \#6". The Sixth Swedish Production Symposium, 2014.

[51] J. Bruch, J. Karltun, K. Dencker. "Assembly Work Settings Enabling Proactivity - Information Requirements". 41 ${ }^{\text {st }}$ CIRP Conference on Manufacturing Systems, Tokyo, Japan, pp. 203-208, 2008.

[52] J. Li. "The Benefit of Being Physically Present: A Survey of Experimental Works comparing Copresent Robots, Telepresent Robots and Virtual Agents". International Journal of Human-Computer Studies, Vol. 77, pp. 23-37, 2015

[53] I. Aaltonen, A. Arvola, I. Heikkil, H. Lammi. "Hello Pepper, May I Tickle You?: Children's and Adults' Responses to an Entertainment Robot at a Shopping Mall'. Proceedings of the Companion of the 2017 ACM/IEEE International Conference on Human-Robot Interaction, Vienna, Austria, 2017.

[54] P. Sweetser, P. Wyeth. "GameFlow: A Model for Evaluating Player Enjoyment in Games". Computers in Entertainment, 3(3):3-3, 2005.
[55] N. Yee. "The Labor of Fun: How Video Games Blur the Boundaries of Work and Play". Games and Culture, Vol. 1, pp. 68-71, 2006.

[56] G. Richter, D.R. Raban, S. Rafaeli. "Studying Gamification: The Effect of Rewards and Incentives on Motivation". In Gamification in Education and Business, pp. 21-46, Springer, 2015.

[57] G.W. Bock, R.W. Zmud, Y.G. Kim, J.N. Lee. "Behavioral Intention Formation in Knowledge Transfer: Examining the Roles of Extrinsic Motivators Social-Psychological Forces, and Organizational Climate". MIS Quarterly, Vol. 29, pp. 87-111, 2005.

[58] S. Dovis. "Cognitive Control and Motivation in Children with ADHD: How Reinforcement Interacts with the Assessment and Training of Executive Functioning”. Amsterdam: University of Amsterdam, 2014.

[59] V. Gay, P. Leijdekkers, A. Pooley. "Building Social Awareness for Teens and Young Adults with Autism via Gamification”. I.T. Marsh et al. (Eds.), Serious Games: $2^{\text {nd }}$. Joint International Conference, JCSG Brisbane, QLD, Australia, September 26-27, pp. 116-127, Springer International Publishing, 2016.

[60] J. Złotowski, D. Proudfoot, K. Yogeeswaran. "Anthropomorphism in Social Robotics: Empirical Results on Human-Robot Interaction in Hybrid Production Workplaces". International Journal of Social Robotics, Vol. 7, p. 347, 2015

[61] Soar Cognitive Architecture - https://soar.eecs.umich.edu/ 